\title{
Modelling the Evolution of the Microstructure of a Nb Steel
}

\author{
J. MAJTA, J. G. LENARD ${ }^{1)}$ and M. PIETRZYK \\ Department of Metallurgy and Materials Engineering, University of Mining and Metallurgy, Krakow, Poland. \\ 1) Department of Mechanical Engineering, University of Waterloo, Waterloo, Canada.
}

(Received on December 8, 1995; accepted in final form on April 12, 1996)

\begin{abstract}
A mathematical model, for the prediction of the evolution of the microstructure during hot forming of microalloyed steels, is presented. The material behavior is combined with a finite-element model of the deformation. Multi-stage, isothermal compression tests are used for verification. The effect of the interruption between stages of compression on the restoration mechanisms is studied in three-stage tests. The influence of the deformation history on the microstructural development and on the softening mechanisms is also analyzed. The distribution of austenite grain sizes is predicted. The inhomogeneity of the resulting structure is connected to that of the mechanical attributes of the deformed material. The studies show that additional grain refinement can be expected by controlling the recrystallization kinetics and the retained strain.
\end{abstract}

KEY WORDS: microstructure evolution; hot compression; microalloyed steels.

\section{Introduction}

Microalloying affects the recrystallization behavior through solute drag and the pinning effect of the precipitates. The mechanisms of these phenomena, formulated on the basis of nucleation and growth theory, have been incorporated in mathematical models, ${ }^{1-6)}$ directly applicable for the analysis of hot deformation of microalloyed steels.

During hot rolling of microalloyed steel strips full recrystallization does not usually occur between passes and a precise description of recrystallization kinetics is necessary for the accurate prediction of microstructural changes. ${ }^{7)}$ The strength depends on the amount of softening in between mill stands. Microstructural development during and after deformation also influences the restoration mechanisms. The retardation of softening is therefore very significant in raising the hot strength of these steels. The history of deformation is also directly connected with the ferrite grain size and will influence the room-temperature properties.

The development of the microstructure influences that of the mechanical properties of the product. Monitoring the development under industrial conditions is difficult. A fully substantiated hot deformation model may prove to be an indispensable tool for process control.

The major advantage of the finite element method is its ability to compute the variations of strain, strain rate, flow stress, temperature, cooling rates and grain sizes and shapes in the deformation zone. The resulting description of the inhomogeneity of the dependent variables may be related well to conditions found in industrial production. In the hot rolling of strips of microalloyed steels, the initial microstructural inhomogeneity in the austenite region, which can be incorporated in the mathematical model as an initial condition, will have a very significant influence on the metallurgical state of the finished product and may well result in highly non-homogeneous mechanical attributes.

This paper describes a model that calculates the microstructural changes in a deformed metal, as well as the influence of the history of deformation on the material behavior. The model, based on the equations of Ref. 2), is incorporated in the finite-element technique of Ref. 9). The predictions are substantiated by comparison to measurements taken after hot compression of microalloyed steels.

\section{Modelling the Evolution of the Microstructure}

At strains below the critical value for dynamic recrystallization the most apparent microstructural changes are grain flattening, subgrain development, static recrystallization and grain growth, $8,10-13$ ) controlling the grain size in the austenite and in the ferrite regions. Quantitative analysis of the microstructural changes during hot rolling was pioneered by Sellars, ${ }^{7,11)}$ relating the hot working variables to the microstructural changes in several steels. The relationships describe the onset of dynamic recrystallization, the kinetics of static recrystallization and the grain size development by static recrystallization as well as the grain growth mechanisms. Revised versions of the equations were added in Ref. 2). A complete set of relations for the evolution of the microstructure, applicable for $\mathrm{Ti}-\mathrm{V}$ steels was given in Ref. 14), considering the influence of the hot rolling procedures on static recrystallization, static recovery and grain growth of austenite in addition to the as-hot-rolled ferrite grain size. The principal variables were the reductions, temperatures, inter-pass times and param- 
eters defining cooling between the finish rolling temperature, FRT, and $\mathrm{Ar}_{3}{ }^{15)}$ focused attention on recrystallization during rolling, whereby a fine, as-rolled grain size was obtained via transformation from the austenite, refined by static recrystallization. Choquet et $a l^{16)}$ described the stress for a single pass, the flow stress and structure in a multipass process and the microstructural evolution following the last pass, employing the constitutive relation of Ref. 17). Empirical equations were proposed for static recrystallization kinetics, in which the interaction between recrystallization and strain induced precipitation was accounted for through the "critical temperature," depending on the Nb content. In Ref. 18) the recrystallization kinetics was based on Sellars' equations. ${ }^{7)}$ Multipass recrystallization and grain growth are significant parts of Ref. 18), correlating well with industrial conditions. The model of Ref. 1) included $\mathrm{Nb}(\mathrm{CN})$ precipitation for predicting the precipitation finish time, based on reaction kinetics and classical nucleation and growth theory. The time exponent and rate constant for a kinetic rule were formulated for growth or for nucleation and growth. The measured and calculated data compared well. The model of Ref. 4) also utilized the classical nucleation and growth theories, proposing the concept of dislocation density to explain the effects of metallurgical processes.

\subsection{Model of the Deformation}

Simulation of metal flow and heat transfer is based on the model of Ref. 9). Rigid-plastic formulation was coupled with the non-steady state solution of the general diffusion equation.

\subsection{Kinetics of Static Recrystallization and Precipita- tion}

Recrystallization kinetics, when the $\mathrm{Nb}$ is in solution, is given in terms of the time for $5 \%$ recrystallization ${ }^{2)}$ :

$$
\begin{aligned}
t_{x 0.05}= & \varepsilon^{-4} 6.75 \times 10^{-20} D_{\mathrm{o}}^{2} \times \exp \frac{300000}{R T} \\
& \times \exp \left\{\left(\frac{2.75 \times 10^{5}}{T}-185\right)[\mathrm{Nb}]\right\}
\end{aligned}
$$

If in the early stages of precipitation the kinetics are dominated by the nucleation rate, the time to achieve a constant, small fraction of precipitate is given by the time for $5 \%$ strain-induced precipitation ${ }^{2,22)}$ :

$$
\begin{aligned}
t_{\mathrm{p} 0.05}= & \varepsilon^{-1} A[\mathrm{Nb}]^{-1} Z^{-0.5} \exp \frac{270000}{R T} \\
& \times \exp \frac{B}{T^{3}\left[\ln \left(k_{\mathrm{s}}\right)\right]^{2}} \ldots \ldots \ldots \ldots \ldots \ldots \ldots \ldots \ldots \ldots
\end{aligned}
$$

Since the dependence of $A$ on the process is unknown, ${ }^{2)}$ a value of $3 \times 10^{-6}$ is used. For $B, 2.5 \times 10^{10}$ is employed. In Eq. (2) $k_{\mathrm{s}}$ represents the supersaturation ratio at temperature $T$ :

$$
k_{\mathrm{s}}=[\mathrm{Nb}][C+12 \mathrm{~N} / 14]_{\mathrm{soln}} / 10^{2.26-6770 / T}
$$

where $C$ and $N$ refer to the concentration of these elements in solution. Titanium is not considered in de- scribing the saturation ratio by Eq. (2-a). Akamatsu et $a .^{19)}$ and Yoshinaga et al. $^{21)}$ considered the effect of $\mathrm{Ti}$ on the precipitation behavior in extra-low carbon steels, containing $\mathrm{Nb}$ and $\mathrm{Ti}$. Even small amounts of $\mathrm{Ti}$ have been found to have considerable effects. Since the extension of these conclusions to steels containing $0.067 \% \mathrm{C}$ is uncertain, the use of Eq. (2-a) may be justifiable. The same equation was used in Ref. 23) when studying steels, containing $\mathrm{Nb}$ without $\mathrm{Ti}$ or $\mathrm{Nb}$ with $0.03 \% \mathrm{Ti}$ as well as in Ref. 20).

\subsection{Fraction of Recrystallized Austenite}

The Avrami equation ${ }^{24)}$ for the fraction of recrystallized austenite assumes that the recrystallized grains are growing independently of one another and they are located at random in the solid. With Eq. (1)

$$
X=1-\exp \left[-0.0513\left(\frac{t}{t_{x 0.05}}\right)^{n}\right]
$$

The exponent, $n$, has been given values from 1.0 to 2.0 in Refs. 15), 14) and 25). For microalloyed steels $n=1.0$ is most satisfactory. ${ }^{26)}$ The time for $x \%$ recrystallization is described by

$$
t_{x}=C^{1 / n} t_{x 0.05}
$$

where $C$, for $90 \%$ recrystallization, is 5.33 . The interactions of $t_{x 0.05}, t_{x 0.90}$ and $t_{\mathrm{p} 0.05}$ determine the influence of the precipitation on the retardation of recrystallization.

\subsection{Austenite Grain Size}

The equation describing the recrystallized grain size $D_{\gamma}$, for microalloyed steels, ${ }^{11)}$ is used:

$$
D_{\gamma}=M D_{0}^{r} \varepsilon^{-m} Z^{-u}
$$

where $r=0.67 ; m=0.67 ; u=0 ; M=$ constant. The total strain is calculated in terms of the effective strain in the previous stage of deformation and an increment ${ }^{5,27)}$ :

$$
\varepsilon=\varepsilon_{i}+\Delta \varepsilon \text { and } \Delta \varepsilon=K \varepsilon_{i-1}(1-X)
$$

where $K$ is a constant, between 0.5 and 1 . Values for $M$ have been given, from 0.66 to $1.86^{20,28)}$ arising from differences in composition. ${ }^{11)}$ Here an equation in terms of the $\mathrm{Nb}$ and $\mathrm{Ti}$ contents is proposed: $M=1-([\mathrm{Nb}+$ [Ti]). As suggested in Ref. 2), $u$ in Eq. (5) should be different from zero and the dependence of the grain size on $Z$ should be incorporated.

\subsection{Static Recovery}

When recrystallization is incomplete between compression stages, the unrecrystallized material will experience static recovery. The effect of precipitation on the kinetics of static recovery is small in comparison to the others, and in what follows, it is ignored.

\subsection{Grain Growth}

The model of grain growth ${ }^{25)}$ is employed in the current work:

$$
D_{\gamma \mathrm{g}}^{z}=D_{\gamma}^{z}+k_{(\mathrm{s})} t \exp \left(-\frac{Q_{\mathrm{g}}}{R T}\right)
$$


where for a $\mathrm{C}-\mathrm{Mn}-\mathrm{Nb}$ steel $k_{(\mathrm{s})}=4.1 \times 10^{23} ; Q_{\mathrm{g}}=435$ $\mathrm{kJ} / \mathrm{mol}$ and $z=4.5$. The retardation of growth is affected by $z$, which is strongly dependent on the composition. ${ }^{11,13,15,28)}$

\subsection{The Steps in the Computations}

After evaluation of the temperature, the strain and the strain rate for each element, the Zener-Hollomon parameter is used to decide if static or dynamic recrystallization follows. The recrystallization and precipitation times are computed for the corresponding conditions of strain, temperature, grain size, strain rate and chemical composition, using Eqs. (1)-(4). If precipitation takes place before recrystallization all strains are treated as retained strains. If partial recrystallization occurs $\left(t_{x 0.05}<t_{\mathrm{p} 0.05}<t_{x 0.90}\right)$, Eqs. (3) and $(5-a)$ are employed. The recrystallized grain sizes are determined by Eq. (5). The changes in the temperature fields and the stress-strain states from step to step are calculated by the thermal-mechanical part of the finite element program.

\section{Experiments}

Equipment: The tests were conducted on an INSTRON $50 \mathrm{kN}$ machine, within a furnace. Data acquisition and control of the servovalve to provide constant, true strain rates during the process are achieved by an attached microprocessor.

Material: The material contains $0.067 \% \mathrm{C}, 1.3 \% \mathrm{Mn}$, $0.076 \% \mathrm{Nb}, 0.024 \% \mathrm{Ti}, 0.34 \% \mathrm{Si}, 0.037 \% \mathrm{Al}, 0.005 \%$ $\mathrm{V}$ and $0.0054 \% \mathrm{~N}$.

Sample preparation: Each sample, $8 \mathrm{~mm}$ in diameter and $12 \mathrm{~mm}$ height, was fitted with a type $\mathrm{K}$ thermocouple, embedded at the midpoint. All samples were annealed, for two hours at $900^{\circ} \mathrm{C}$, and air cooled. Solution treatment at $1225^{\circ} \mathrm{C}$ for $20 \mathrm{~min}$ and quenching in water followed, ensuring that most alloying elements are in solution at the start of the tests. Thermal treatments were conducted in a quartz tube, filled with zirconium shavings.

Procedure: The samples, coated with the lubricant

a)

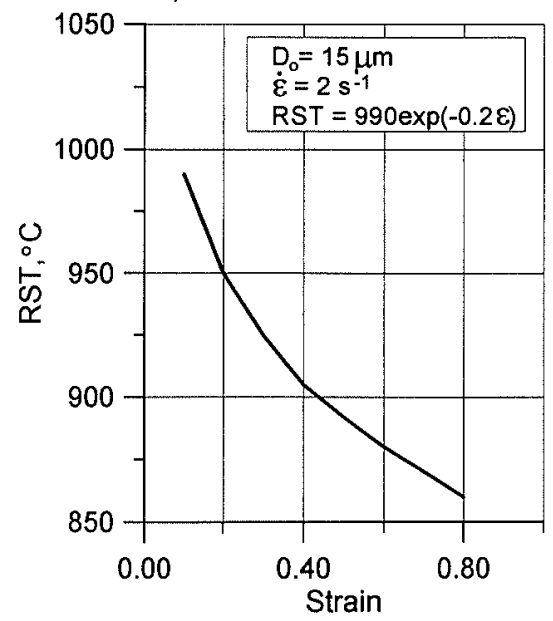

are placed on the compression ram of the preheated furnace. After compression, they were quenched at a rate of approximately $500^{\circ} \mathrm{C} / \mathrm{s}$, sufficiently fast to freeze the austenite grain structure. Isothermal, single- and three-stage tests were conducted at $975^{\circ} \mathrm{C}$, which is near the zone of the recrystallization-step temperature (RST), the dependence of which on the strains, a predicted by the relation $\mathrm{RST}=990 \exp (-0.2 \varepsilon)$ is used in Fig. 1(a). Figure 1(b) shows a comparison of the RST calculated by the present model with the results of Refs. 8) and 28), for similar steels and conditions. In the calculations the RST was taken to occur when the time for $5 \%$ recrystallization equals the time for $5 \%$ strain induced precipitation. $^{2)}$ In the multi-stage tests, the strain of 0.37 was applied in each stage, chosen to avoid dynamic recrystallization during prestraining. In the deformation process, the sample was deformed to a true strain of 0.37 , unloaded and reloaded to a strain of 0.74 , unloaded and loaded again to a total final strain of 1.1. The deformation was at a constant, true strain rate of $2 \mathrm{~s}^{-1}$. The interruption times were $0.3,3,10$ and $20 \mathrm{~s}$. These delay times were also used after full compression before quenching. During interrupted compression tests the delay time was constant for each stage.

\section{Results and Analysis}

\subsection{True Stress-True Strain Curves}

The single stage true stress/true strain curve, performed at $975^{\circ} \mathrm{C}$ and at a constant strain rate of $2 \mathrm{~s}^{-1}$, indicates that under the present conditions strains beyond 0.55 are required to induce dynamic restoration. The peak strength is $163 \mathrm{MPa}$, showing the increased hot strength produced by the niobium. The three-stage tests were designed using the information, obtained from the single stage flow curve; the level of prestrain, 0.37 . was selected to permit the study of the softening response in which static recrystallization is the only restoration process after prior deformation.

The interrupted flow curves are shown in Figs. 2(a), 2(b), 2(c) and 2(d). The delay time in the unloading period

b)

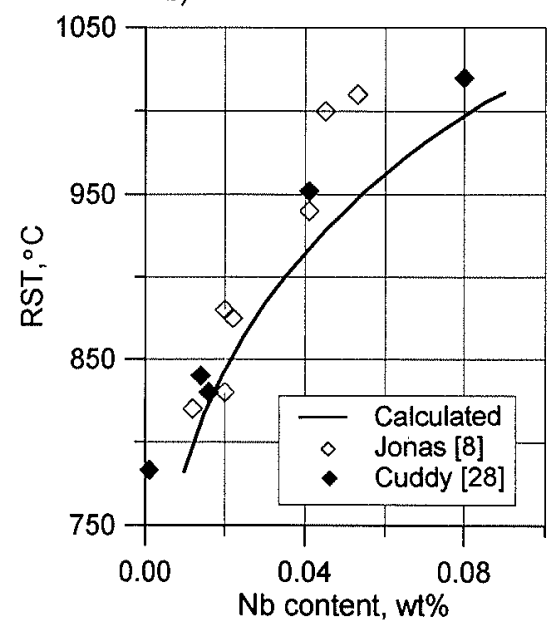

Fig. 1. Dependence of recrystallization-stop temperature, RST, on strain and niobium content in solution; a) conditions for a numerical experiment, b) comparison of RST, calculated by the present model vs. the observations of Jonas et al. ${ }^{10,44)}$ and Cuddy. ${ }^{35)}$ 
a)

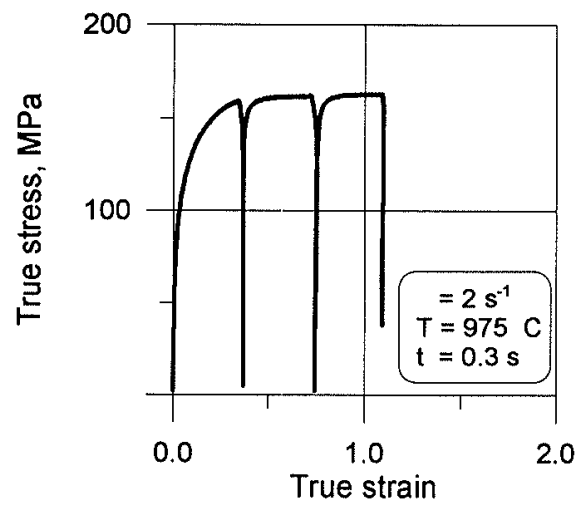

c)

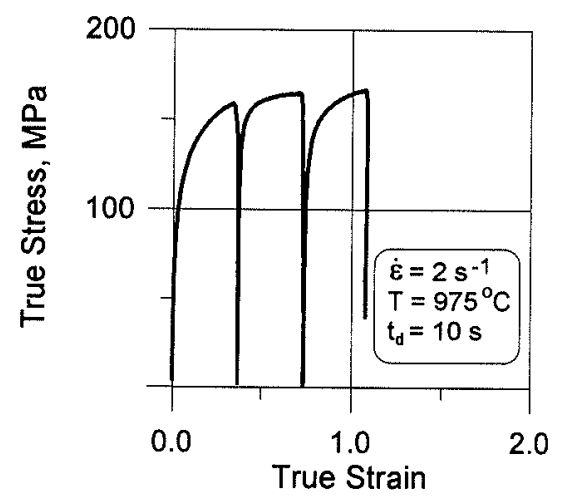

b)

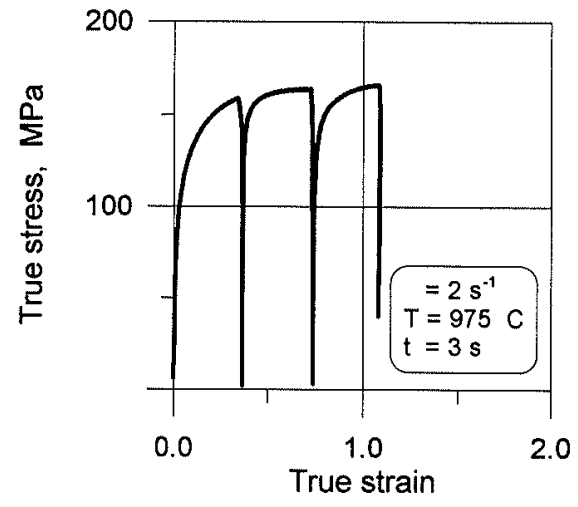

d)

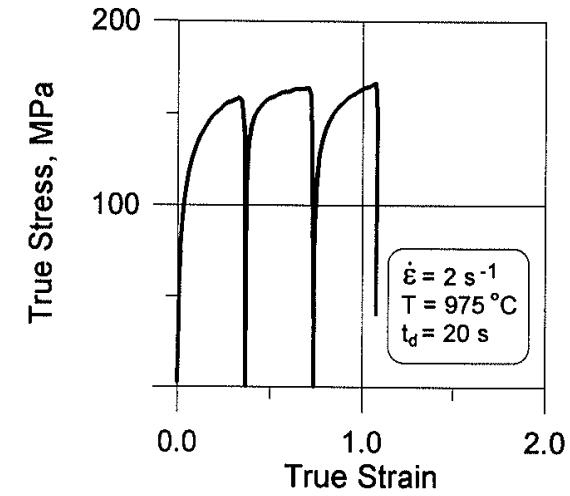

Fig. 2. Effect of delay time on the subsequent stress-strain behavior, during two interruptions, a) $t_{\mathrm{d}}=0.3 \mathrm{~s} ; \mathrm{b}$ ) $\left.\left.t_{\mathrm{d}}=3 \mathrm{~s} ; \mathrm{c}\right) t_{\mathrm{d}}=10 \mathrm{~s} ; \mathrm{d}\right) t_{\mathrm{d}}=20 \mathrm{~s}$.

is varied; in a) it is $0.3 \mathrm{~s}$, in b) it is $3 \mathrm{~s}$, in c) and d), 10 and $20 \mathrm{~s}$, respectively. The shapes of the curves under these conditions indicate that the dislocation density during plastic flow, after this critical amount of deformation, was limited by the annihilation of dislocations and that no dynamic recrystallization was taking place. The curves in the first stage are similar for all experiments. The softening effect increases when the delay time is increased. The increasing softening in the second interruption, for each of the delay times, is also observed, caused by the lack of full static recrystallization during the first interruption. The strains accumulate from stage to stage and the combined effects of the mechanisms of softening, static recrystallization and eventual recovery, after the longer delay times, affect the second unloading period. This softening process, however, is effectively retarded by the presence of straininduced precipitation. The degree of retardation in recovery is related to the volume fraction of precipitation and the amount of prestrain. $\mathrm{Nb}(\mathrm{CN})$ precipitation results in an increase in the incubation time for austenite recrystallization as well as a much slower recrystallization growth rate. ${ }^{6}$ Strain-induced $\mathrm{Nb}(\mathrm{CN})$ precipitation from hot worked austenite occurs in two stages: (a) initial precipitation at prior austenite grain boundaries and deformation bands, and (b) general matrix precipitation on the substructure of the unrecrystallized austenite. If austenite recrystallization precedes the precipitation, the latter sets in relatively slowly. ${ }^{6}$ )

Incomplete recrystallization during interruption I increases the stored energy with the accumulated strain and the kinetics of recrystallization is more sensitive to strain then the kinetics of precipitation, resulting in more effective softening, also indicated by Eqs. (1) and (2), above. The delay time is the most significant process parameter that controls the dynamics of the softening process. Work hardening in stage III is generally less than in stage II but still higher than for the fully annealed metal. This indicates that significant, but not full, static recrystallization occurred during interruption II, causing additional grain refinement, in addition to some so far unrecrystallized, deformed grains. The different interactions of recrystallization and precipitation for different delay times can be well explained, as in Ref. 10). When short interpass times are employed, precipitation induced by the strains prior to the interruption is absent and the RST depends solely on the solute drag. With intermediate times recrystallization in $\mathrm{Nb}$ steels is retarded by precipitation. When the interpass time is sufficiently long precipitate coarsening leads to a decrease in particle density and therefore to a weakening of the drag force.

\subsection{Fractional Softening}

With the initial austenite grain size of $15 \mu \mathrm{m}$, the degree of softening is calculated using the offset method, the principles of which and a comparison of its accuracy to other methods are given in Refs. 26), 27), 29). Figures 3 and 4 show the results, in interruptions I and II, respectively. The rate of softening following the second unloading period is observed to be higher than in the 
ISIJ International, Vol. 36 (1996), No. 8

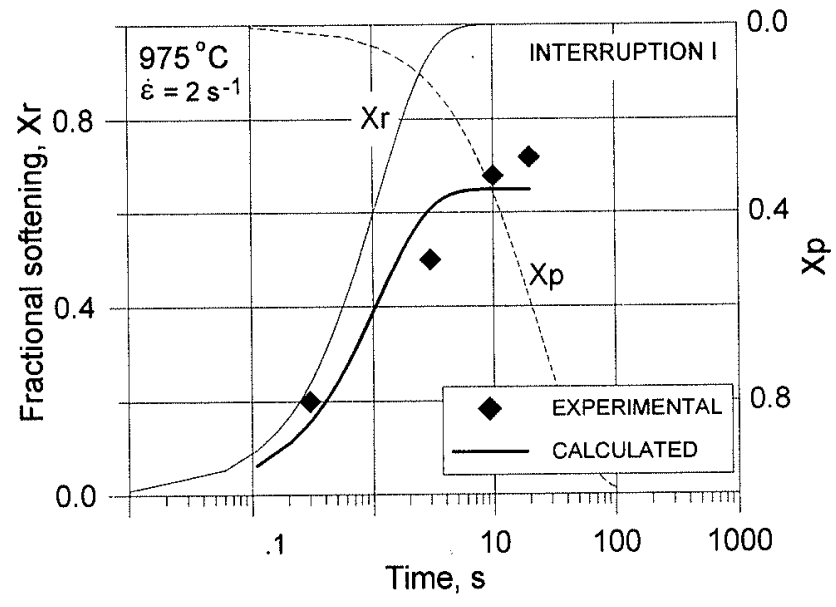

Fig. 3. Measured and predicted fractional softening after the first interruption. $X r, X p$-kinetics calculated separately for static recrystallization and strain induced precipitation, respectively.

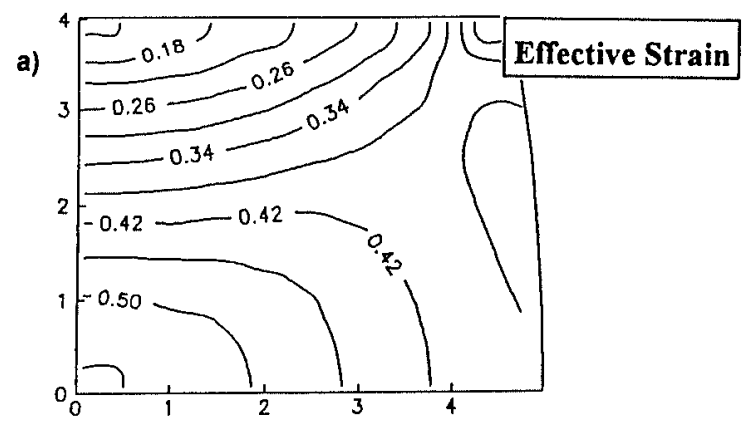

b)

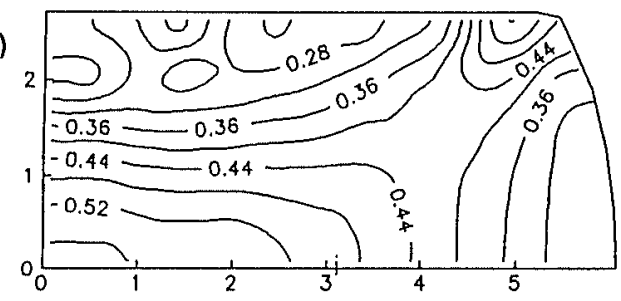

c)

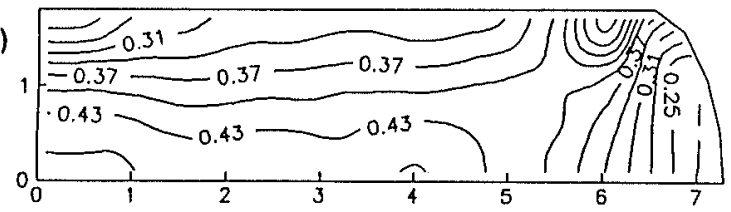

Austenite Grain Size

d)

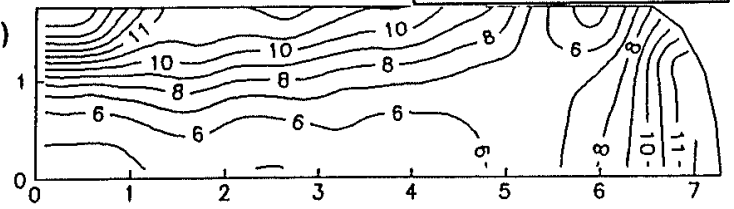

Fig. 5. Distribution, on the cross section, of the effective strain after a) first, b) second, c) third stage of compression, and d) distribution of recrystallized austenite grain size of the fully compressed specimen. Delay time: $t_{\mathrm{d}}=3 \mathrm{~s}$.

first one. The curves, $X r$ and $X p$, representing the kinetics of recrystallization and precipitation, are also shown. The results indicate good agreement with the experimental data and verify the predictive ability of the model of microstructural development.

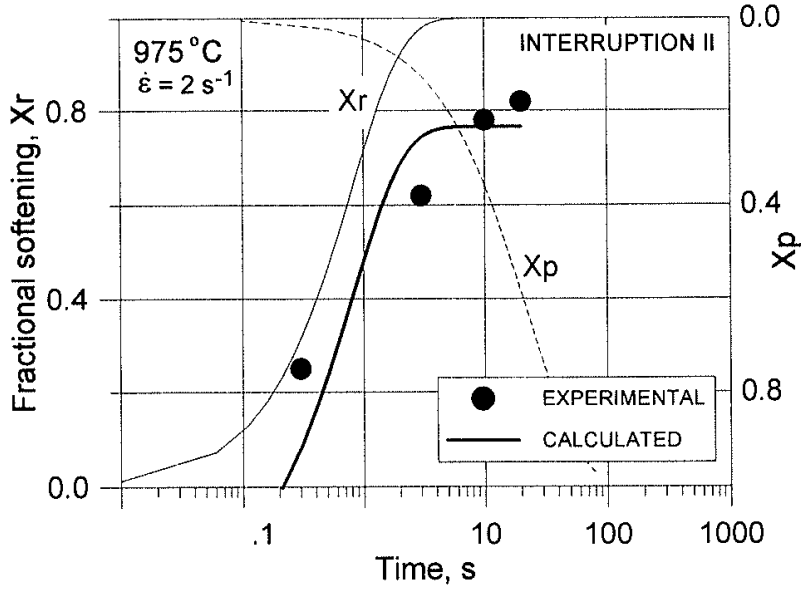

Fig. 4. Measured and predicted fractional softening after the second interruption. $X r, X p$-kinetics caclulated separately for static recrystallization and strain induced precipitation, respectively.

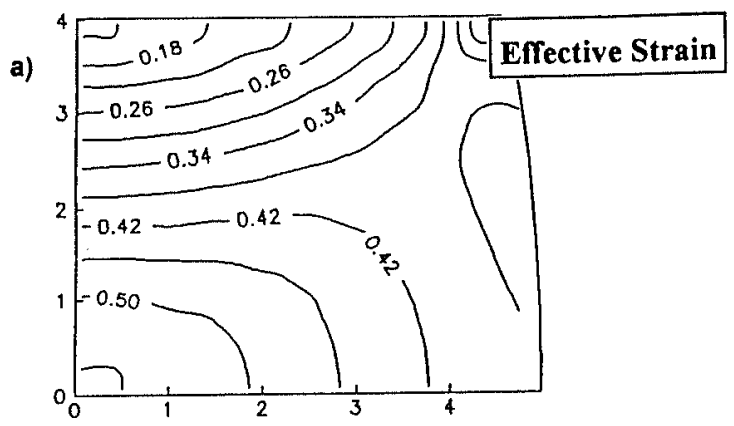

b)

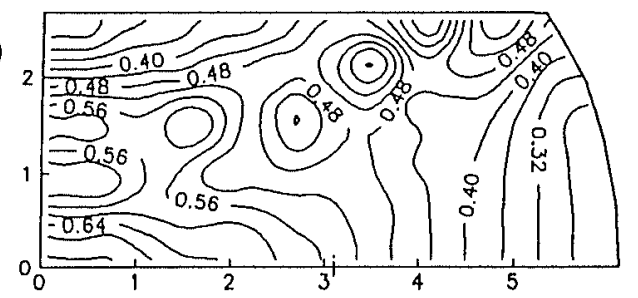

c)

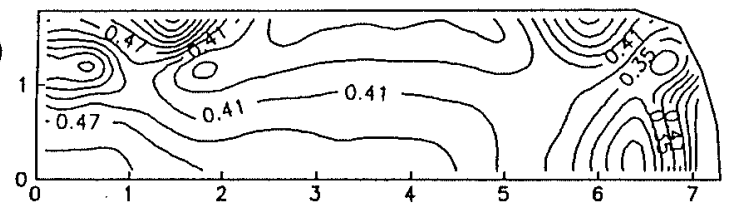

d)

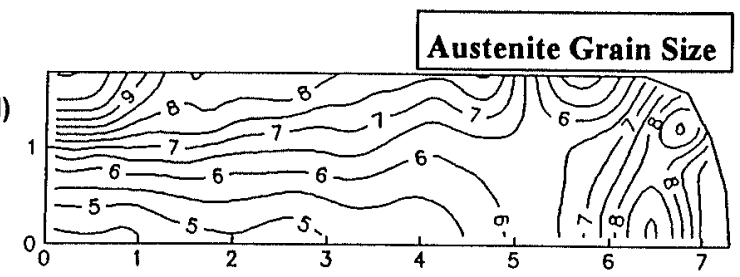

Fig. 6. Distribution, on the cross section, of effective strain after a) first, b) second, c) third stage, and d) distribution of recrystallized austenite grain size of the fully compressed specimen. Delay time: $t_{\mathrm{d}}=0.3 \mathrm{~s}$.

\subsection{Distribution of the Strains and the Austenite Grains}

Figures 5 and 6 present the strain distribution after each experiment - parts a), b) and c) —in addition to the distributions of the austenite grains-part d). The figures show the development of the distributions in two 

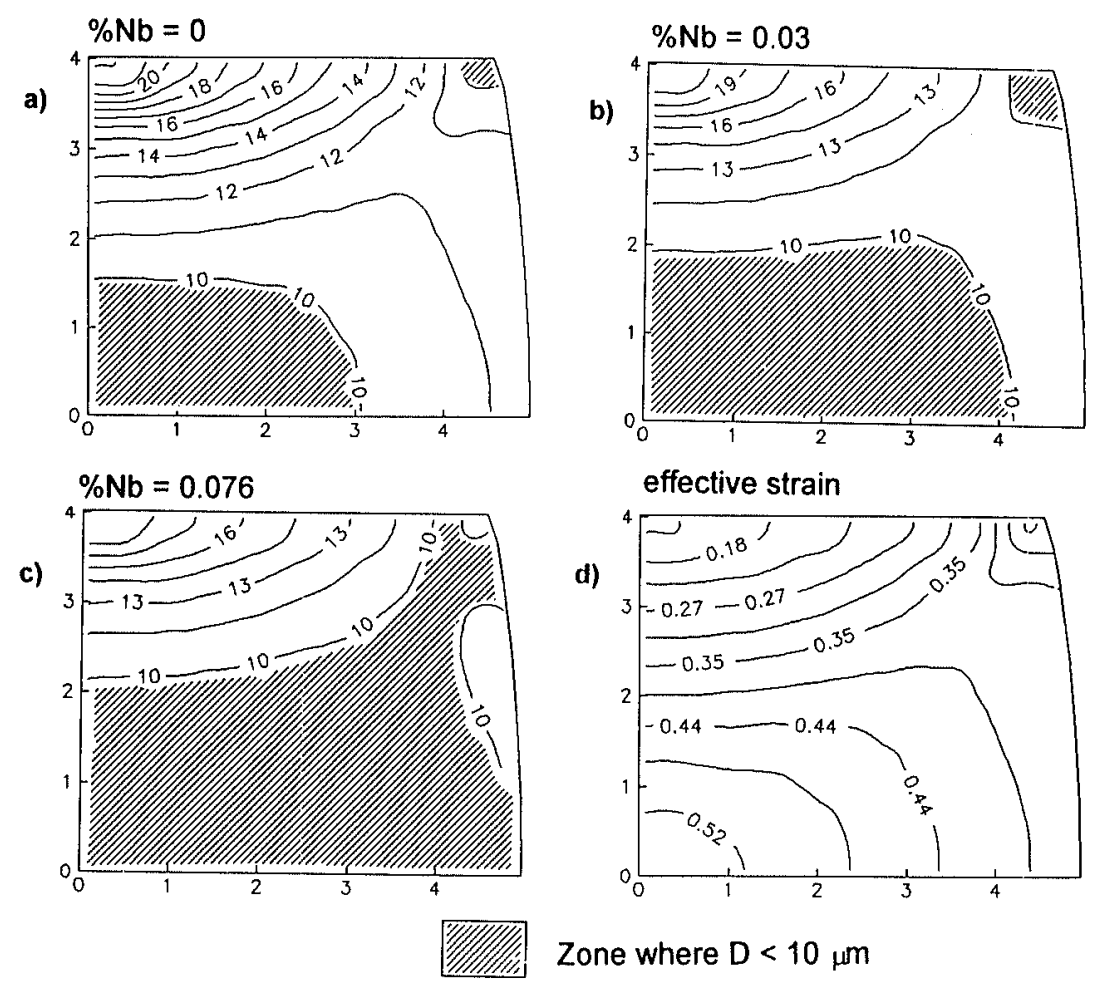

Zone where $\mathrm{D}<10 \mu \mathrm{m}$

Fig. 7. Progress in austenite grain refinement $v s$. Nb content, in solution-a), b), c), and distribution of the effective strain-d). Deformation conditions: one-stage compression at a temperature of $975^{\circ} \mathrm{C}, D_{0}=15 \mu \mathrm{m}$, strain rate $2 \mathrm{~s}^{-1}$. Base chemical steel composition, in wt $\%: 0.067 \% \mathrm{C}, 1.3 \% \mathrm{Mn}, 0.34 \% \mathrm{Si}, 0.025 \% \mathrm{Ti}$, $0.0054 \% \mathrm{~N}$.

characteristic situations. If the delays during the interruptions are long enough-3 $\mathrm{s}$ in Fig. 5-the distributions of strains after stages II and III are typical for a fully annealed material. When static recrystallization doesn't occur, because the delay is too short, shown in Figs. 6(b) and 6(c) for $0.3 \mathrm{~s}$, the accumulated strains are significant and their distributions have been determined, as a result of the complete history, including not only the deformation but also of the microstructural development. The distributions of austenite grain sizes, in Figs. 5(d) and 6(d), show that when the steel's deformation history is as presented in Fig. 6, the final austenite grain size is generally smaller and an improvement of the homogeneity is observed.

Figures 7(a) to 7(d) present the results using the same basic components but different amounts of niobium. The effect of increasing niobium content on the retardation of the grain growth is clearly demonstrated.

The initial austenite grain size controls the mechanical properties in the non-recrystallization region. Even if the correlation between the initial and final austenite grain sizes, after many stages of deformation, is of little significance, the effect of inhomogeneity of the material on the properties, as a result of plastic flow, is still important.

The major microstructural changes after deformation are caused by recrystallization, whose rate depends on the driving force, the density of nucleation sites, and the temperature. ${ }^{7)}$ In terms of the deformed structure, the rate depends on local differences in dislocation density since these provide the driving force, the grain size and the subgrain size, since nucleation occurs preferential- ly at grain boundaries. The effects of a finer initial austenite grain size and less dissolved $\mathrm{Nb}$ on the kinetics of recrystallization ${ }^{30}$ ) indicate that the extent of recrystallization is considerably greater after reheating above the grain coarsening temperature. Higher $\mathrm{Nb}$ contents had a decreasing effect on the grain size. Niobium refined the austenite grain size at temperatures up to $1200^{\circ} \mathrm{C}$, the major effect being produced by up to $0.07 \% \mathrm{Nb}$ while higher contents produced little further refinement. $\mathrm{Nb}$ can retard recrystallization at high temperatures by a solute drag effect, inhibiting nucleation, rather than the growth of recrystallizing grains. At lower temperatures, where strain induced $\mathrm{Nb}(\mathrm{CN})$ precipitation occurs, the retardation is even more pronounced because precipitation inhibits nucleation and growth of the recrystallized grains. ${ }^{30}$ ) Refinement of the initial grain size decreases the critical reduction necessary for recrystallization. The austenite grains were refined with increasing deformation and/or decreasing temperatures above the critical reduction for recrystallization. Grain coarsening in similar steels was caused by light rolling at reductions below $10 \%{ }^{31)}$ This effect is observed in Fig. 7, particularly for low $\mathrm{Nb}$ contents. In general, refined initial austenite grains reduce the number of coarse austenite grains and diminish the uniformity of the austenite grain structure. ${ }^{31)}$

\subsection{Grain size Distribution}

Figure 8 gives the changes of the austenite grain size as a function of the reheating temperature and Fig. 9 shows the sensitivity of the model to different initial structures. The initial austenite grain size controls the 
size of the unrecrystallized grains as well as the inhomogeneity of the recrystallized structure. The most common procedure to control the initial grain size is the reheating temperature prior to the deformation. Low reheating temperatures, below $1070^{\circ} \mathrm{C}$, prevent austenite grain growth because the $\mathrm{NbC}$ and $\mathrm{TiN}$ particles pin the grain boundaries. The lower reheating temperature also reduces the rate of grain-boundary migration and this directly contributes to a fine austenite grain size. ${ }^{32)}$ The results of calculations for grain sizes of $D_{\mathrm{o}}=15,30,50$ and $80 \mu \mathrm{m}$, show significant differences. It is shown that grain size heterogeneity is a necessary requirement for grain growth to occur. The driving force for grain growth increases with increasing heterogeneity and decreases with increasing matrix grain size, ${ }^{33}$ ) explaining the unexpected growth of grains which are

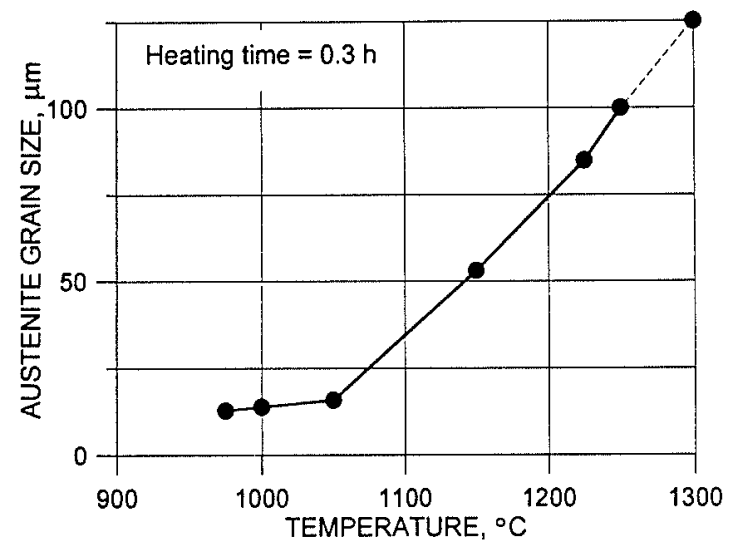

Fig. 8. Variation of the austenite grain size with the heating temperature for the present steel.
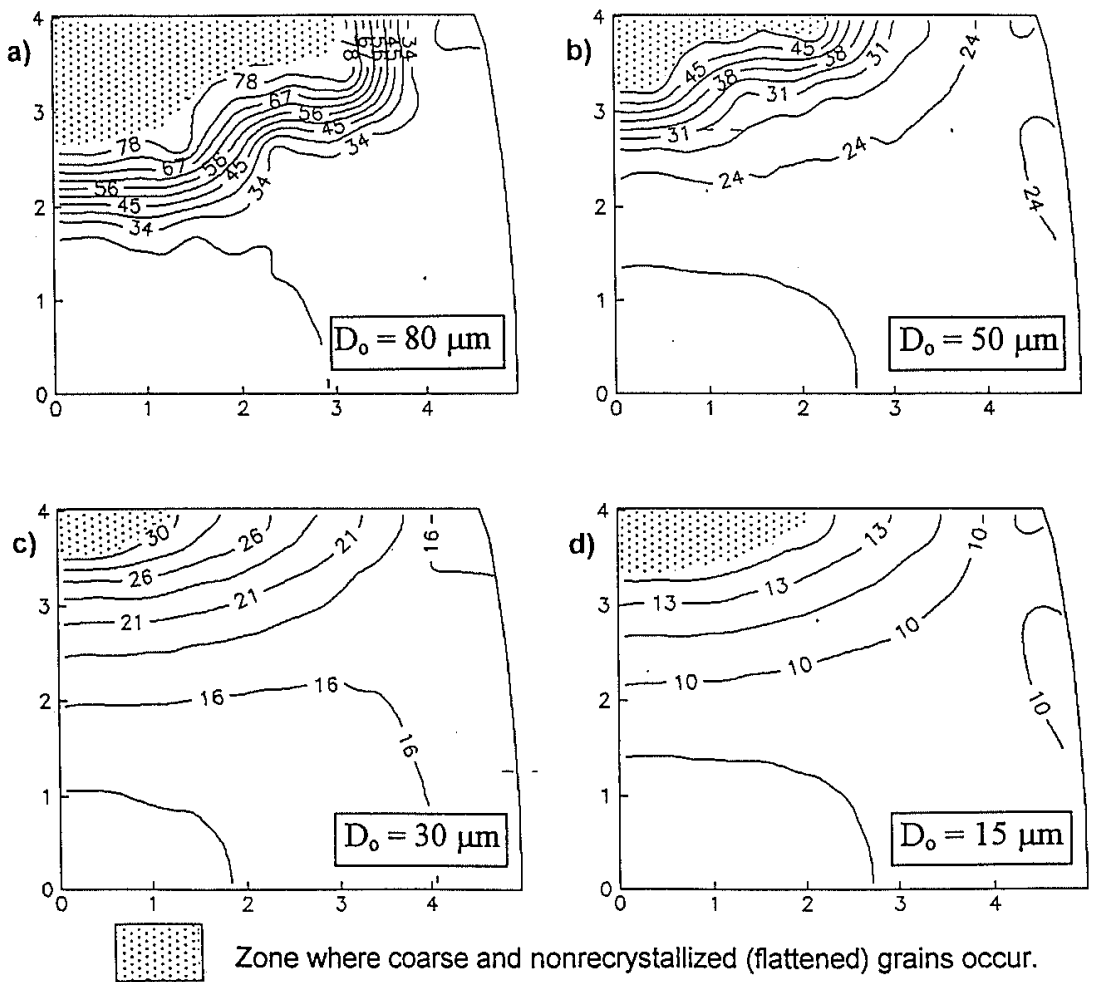

Fig. 9. Progress in austenite grain refinement $v s$. initial grain size-a) $D_{0}=80 \mu \mathrm{m}, T_{\mathrm{R}}=1225^{\circ} \mathrm{C}$; b) $D_{0}=50 \mu \mathrm{m}$, $T_{\mathrm{R}}=1150^{\circ} \mathrm{C} ;$ c) $\left.D_{0}=30 \mu \mathrm{m}, T_{\mathrm{R}}=1100^{\circ} \mathrm{C} ; d\right) D_{0}=15 \mu \mathrm{m}, T_{\mathrm{R}}=975^{\circ} \mathrm{C}$. Deformation conditions: one-stage compression at $975^{\circ} \mathrm{C}$, strain rate $2 \mathrm{~s}^{-1}$. Base chemical steel composition, in wt \%: $0.067 \% \mathrm{C}, 1.3 \% \mathrm{Mn}$, $0.076 \% \mathrm{Nb}, 0.34 \% \mathrm{Si}, 0.025 \% \mathrm{Ti}, 0.0054 \% \mathrm{~N}$. a large reduction per pass is needed to recrystallize and refine the coarse austenite grains in a mixed grain structure. Figure 9(d) also shows that for small grain sizes the grain distribution gradient is quite small. For rapid beyond the critical value of the strain $-0.25-0.30$ in Fig. 7(d). The observations in Ref. 34) also illustrate tallization increases with increasing initial grain sizes. strain of 0.29 is necessary for full recrystallization of the part of recrystallized austenite has the same size, $34 \mu \mathrm{m}$. more difficult than for a more refined structure and the lated and retained work hardening increases the driving force for restoration, which in turn increases the rate of these processes. ${ }^{27)}$ These effects involve rapid recrystallization-see Fig. 9(a). tenite grain boundaries and are frequently observed at crystallization proceeds more uniformly and easier in structures of smaller grains. However, the start-up of recrystallization is highly nonuniform, and even as it nonuniform grains were more difficult to recrystallize than uniform, coarse grains. ${ }^{31)}$ The results suggest that larger grain sizes, Fig. 9(a), recrystallization is more how rapidly the critical reduction necessary for recrys-

For coarse grain structures (Fig. 9(a)) an effective austenite. ${ }^{35)}$ No influence of increasing deformation on further refinement of the austenite was observed, supporting the computations of Fig. 9(a), where a large

With large grains the progress of recrystallization is stored deformation energy must increase. The accumu-

Recrystallized grains nucleate predominantly at austhe intersection of three grains, ${ }^{6)}$ explaining why reproceeds, many of the austenite boundaries remain in- 


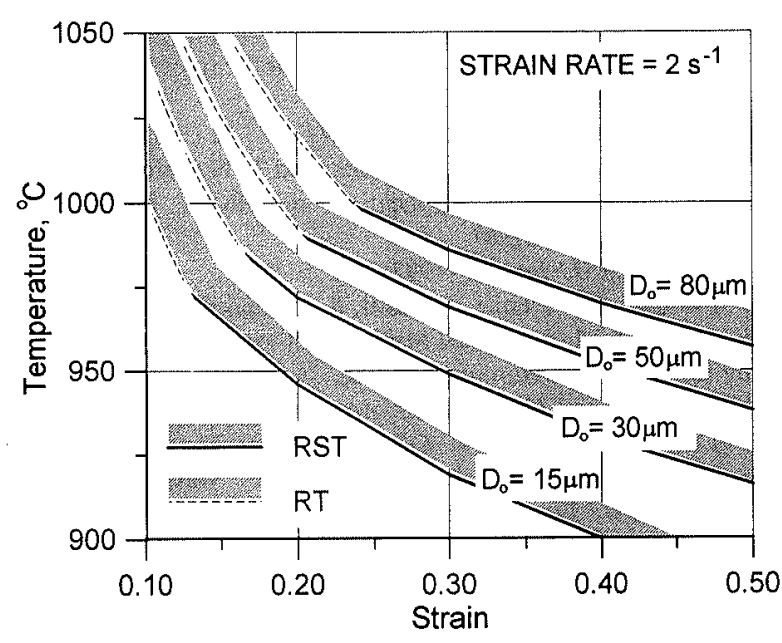

Fig. 10. Relation between recrystallization temperature (TR), recrystallization stop temperature (RST) and strain for different initial austenite grain sizes.

activate as nucleation sites.

The rate of a transformation/volume, $d x / d t$, can be described by ${ }^{36}$ )

$$
\frac{d x}{d t}=G_{x} S_{\mathrm{v}}
$$

In Ref. 6) $G_{x}$ decreased rapidly during the initial stages of recrystallization, slowing down later. The rates also decrease with increasing niobium in solution prior to deformation. For example, considering a steel containing $0.069 \% \mathrm{Nb}$ in solution, heating it to $1250^{\circ} \mathrm{C}$, and rolling to $50 \%$ reduction at $950^{\circ} \mathrm{C}$, up to $25 \%$ of the volume recrystallized, the recrystallization growth rates rapidly decreased and stabilized at a lower level. When the solution treatment was done at $1100^{\circ} \mathrm{C}$, this process happened more slowly without rapid changes, shown in Figs. 9(a) and 9(d).

The alloying elements in solution, resulting from different heat treatments, play a significant role in the development of the grain structures, affecting the precipitation-recrystallization interactions. Figure $\mathbf{1 0}$ shows this effect as a function of the initial austenite grain size, giving a tool to aid the design of hot deformation schedules for $\mathrm{Nb}$ steels. In the figure $\mathrm{RT}$ denotes the temperature at which holding for less than $3 \mathrm{~s}$ after deformation will cause $5 \%$ recrystallization. The regions above the lines indicate conditions where recrystallization may begin. Since the major phenomenon retarding recrystallization is strain induced precipitation, Fig. 10 shows that for small strains its progress is determined by RT. This effect increases when $D_{0}$ increases. The critical value of the strain necessary for recrystallization also increases with the initial grain size, explaining the situation of Fig. 9. The very strong correlation between the initial grain size and the minimum deformation temperature necessary for recrystallization is also shown in Fig. 10. For example, for a strain of 0.3 and $D_{\mathrm{o}}=15 \mu \mathrm{m}$, recrystallization will effectively stop at $920^{\circ} \mathrm{C}$ while for $D_{0}=80 \mu \mathrm{m}$ no recrystallization can be expected before $985^{\circ} \mathrm{C}$. Similar behavior was observed by Cuddy, ${ }^{37)}$ investigating the relationship between the initial austenite grain size and the RST for several microalloyed steels. He found that if $D_{\mathrm{o}}$ increases from 35 to $120 \mu \mathrm{m}$, the RST increases from 810 to $920^{\circ} \mathrm{C}$. It is realized, of course, that the influence of the initial grain size on the RST is very complex, affected by the deformation conditions and chemical composition of the metal.

If, in the deformed steel, the austenite is partially recrystallized because of insufficient reductions or low temperatures, a mixture of fine recrystallized austenite grains will develop with large unrecrystallized grains. This structure, after deformation, transforms to a fine but nonuniform ferrite structure, ${ }^{35)}$ causing redundant inhomogeneity of the mechanical properties of the product.

\section{Conclusions}

A mathematical model, incorporating relations that describe the evolution of the microstructure of microalloyed steels, subjected to multi-stage hot forming, with a rigid-plastic finite element method, has been presented. The model accounts for the restoration mechanisms, the hardening events and the accumulation of strains. The reasonable predictive capabilities of the technique have been demonstrated by comparing the calculated magnitudes of fractional softening in a three-stage compression test of a high niobium steel to that of measurements. The capabilities of the model were further indicated by several numerical experiments in which the strain distribution, as affected by the retained strains and the austenite grain distribution, was computed. Further, the effect of the niobium content on its ability to retard grain growth was displayed.

\section{Acknowledgements}

This study was conducted during Dr. Majta's visit at the University of Waterloo. The financial assistance of the NSERC of Canada, MRCO and NATO is gratefully acknowledged.

\section{Nomenclature}

$\begin{aligned} A, B: & \text { constants } \\ c_{\mathrm{p}}: & \text { specific heat } \\ C: & \text { carbon content (Eq. (2-a)); constant } \\ & (\text { Eq. }(4)) \\ D_{\mathrm{o}}: & \text { original grain size } \\ D_{y}: & \text { recrystallized grain size } \\ D_{\gamma \mathrm{g}}: & \text { grain size after grain growth } \\ \mathbf{F}: & \text { vector of boundary tractions } \\ G_{x}: & \text { average migration rate of moving } \\ & \text { boundaries } \\ k: & \text { conductivity } \\ k_{\mathrm{s}}: & \text { supersaturation ratio } \\ R: & \text { universal gas constant } \\ S: & \text { contact surface } \\ S_{\mathrm{v}}: & \text { interfacial area, Eq. }(7) \\ T: & \text { temperature } \\ T_{\mathrm{D}}: & \text { deformation temperature } \\ T_{\mathrm{R}}: & \text { reheating temperature } \\ t: & \text { time } \\ t_{\mathrm{d}}: & \text { delay time } \\ t_{x}: & \text { recrystallization time } \\ & \end{aligned}$




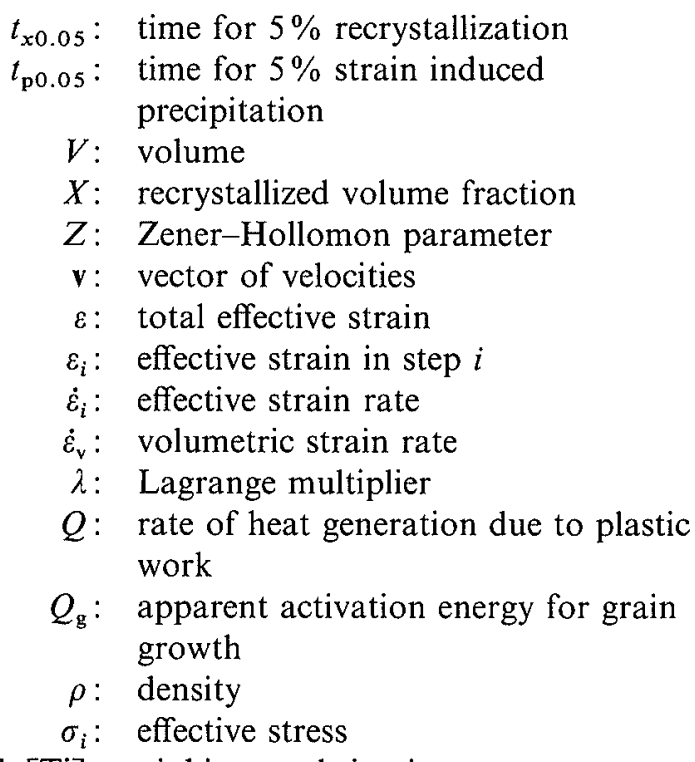

$[\mathrm{Nb}],[\mathrm{Ti}]$ : niobium and titanium contents, in solution

$r, u, m, k_{(\mathrm{s})}, z: \quad$ material and process dependent constants

\section{REFERENCES}

1) S. H. Park, S. Yue and J. J. Jonas: Metall. Trans., 23A (1992), 1641.

2) B. Dutta and C. M. Sellars: Mater. Sci. Technol., 3 (1987), 197.

3) I. Tamura: THERMEC-88, ed. by I. Tamura, ISIJ, Tokyo, (1988), 1.

4) S. Akamatsu, T. Senuma and H. Yada: Mathematical Modeling of Hot Rolling of Steel, ed. by S. Yue, CIM, Hamilton, (1990), 467.

5) T. Siwecki: Proc. Int. Symp. Microalloyed Vanadium Steels, ed. by M. Korchynsky, S. Gorczyca and M. Blicharski, Krakow, (1991), 63.

6) H. Yada: Proc. Int. Symp. Accelerated Cooling of Rolled Steel, ed. by G. Ruddle and A. F. Crawley, Pergamon Press, Winnipeg, (1987), 105.

7) C. M. Sellars and J. A. Whiteman: Met. Sci., 13 (1979), 187.

8) J. J. Jonas: Mathematical Modeling of Hot Rolling of Steel, ed. by S. Yue, CIM, Hamilton, (1990), 99.

9) M. Pietrzyk and J. G. Lenard: Thermal Mechanical Modelling of the Flat Rolling Process, Springer-Verlag, Berlin, (1991)

10) I. Weiss and J. J. Jonas: Metall. Trans., 10A (1979), 831.

11) C. M. Sellars: Proc. Hot Working and Forming Processes, ed. by C. M. Sellars and G. J. Davies, London, (1979), 3.

12) C. M. Sellars: Proc. Def., Processing and Structure, ed. by G. Krauss, St. Louis, (1982), 245.

13) J. H. Beynon and C. M. Sellars: ISIJ Int., 32 (1992), 359.

14) W. Roberts, A. Sandberg, T. Siwecki and T. Warlefors: Int. Conf. on Technology and Application of HSLA Steels, ASM, Philadelphia, (1983), 67.

15) T. Siwecki: ISIJ Int., 32 (1992), 368.

16) P. Choquet, P. Fareque, J. Giusti, B. Chamont, J. N. Pezant and F. Blanchet: Mathematical Modeling of Hot Rolling of Steel, ed. by S. Yue, CIM, Hamilton, (1990), 34.

17) H. Mecking and U. F. Kocks: Acta Metall., 29 (1981), 1865.

18) P. D. Hodgson and R. K. Gibbs: ISIJ Int., 32 (1992), 1329.

19) S. Akamatsu, M. Hasebe, O. Akisue, Y. Matsumura and T. Senuma: ISIJ Int., 34 (1994), 9.

20) D. Q. Bai, S. Yue, W. P. Sun and J. J. Jonas: Metall. Trans., 24A (1993), 2152.

21) N. Yoshinaga, S. Akamatsu, O. Akisue and K. Ushioda: ISIJ Int., 34 (1994), 24.

22) B. Dutta, E. Valdes and C. M. Sellars: Acta Metall. Mater., 40 (1992), 653.

23) R. K. Gibbs, P. D. Hodgson and B. A. Parker: Recrystallization '90, ed. by T. Chandra, Minerals, Met. Mater. Soc., (1990), 585.

24) M. Avrami: J. Chem. Phys., 7 (1939), 1103.

25) P. D. Hodgson and R. K. Gibbs: Mathematical Modeling of Hot Rolling of Steel, ed. by S. Yue, CIM, Hamilton, (1990), 76.

26) A. Laasraoui and J. J. Jonas: Metall. Trans., 22A (1991), 151.

27) H. L. Andrade, M. G. Akben and J. J. Jonas: Metall. Trans., 14A (1983), 1967.

28) L. J. Cuddy: Metall. Trans., 12A (1981), 1313.

29) R. A. P. Djaic and J. J. Jonas: J. Iron Steel Inst., 210 (1972), 256.

30) R. K. Amin and F. B. Pickering: Thermomechanical Processing of Microalloyed Austenite, ed. by A. J. DeArdo, G. A. Ratz and P. J. Wray, AIME, Pittsburgh, (1981), 1.

31) M. Katsumta, M. Machida and H. Kaji: Thermomechanical Processing of Microalloyed Austenite, ed. by A. J. DeArdo, G. A. Ratz and P. J. Wray, AIME, Pittsburgh, (1981), 101.

32) R. Priestner, C. C. Earley and J. H. Rendall: J. Iron Steel Inst., 206 (1968), 1252.

33) T. Gladman: Proc. Roy. Soc. London, A, 294 (1966), 298.

34) T. Tanaka, N. Tabata and T. Hatomura: Microalloying ' 75 , Union Carbide Corp., New York, (1976), 107.

35) L. J. Cuddy: Metall. Trans., 15A (1984), 87.

36) J. W. Cahn and W. C. Hagel: Acta Metall., 11 (1963), 561.

37) L. J. Cuddy: Thermomechanical Processing of Microalloyed Austenite, ed. by A. J. DeArdo, G. A. Ratz and P. J. Wray, AIME, Pittsburgh, (1981), 129. 